\title{
Artificial Neural Network Modeling of High Pressure Descaling Operation in Hot Strip Rolling of Steels
}

\author{
Ahmad KERMANPUR, ${ }^{1)}$ Abbas EBNONNASIR, ${ }^{11}$ Ali Reza Key YEGANEH ${ }^{2)}$ and Jahangir IZADI' ${ }^{31}$ \\ 1) Department of Materials Engineering, Isfahan University of Technology, Isfahan 84156-83111, Iran. \\ E-mail: ahmad_k@cc.iut.ac.ir $\quad$ 2) Mobarakeh Steel Company, Hot Strip Mill, Technical Group, Isfahan, Iran. \\ 3) Mobarakeh Steel Company, Isfahan, Iran.
}

(Received on November 7, 2007; accepted on April 21, 2008)

\begin{abstract}
High pressure (HP) hydraulic descaling is usually used in hot strip mills to remove oxide scales from steel strip formed after the reheat furnace and during hot rolling. In the present work, an artificial neural network (ANN) model was developed to improve efficiency of the HP hydraulic descaling operation using flat spray nozzles. The model was trained based on the industrial data from the hot strip rolling mills of Mobarakeh Steel Complex. The spray angle, inclination angle, spray pressure, vertical spray height and water flow rate were all considered as the main input parameters of the HP descaling operation.

The ANN model developed is able to predict spray impact, spray width and spray depth for any given spray nozzle system. The model can also analytically compute the spray overlap for a given spray nozzle arrangement. A sensitivity analysis was carried out using the ANN model. It was shown that, among all process parameters, the spray angle followed by the inclination angle are the most important parameters affecting the spray impact. The model developed can be used as a proper tool to improve the efficiency of the descaling system in terms of achieving the highest spray impact and an optimum spray overlap for any process condition.
\end{abstract}

KEY WORDS: high pressure hydraulic descaling; hot strip steel rolling; neural network modeling; analytical modeling.

\section{Introduction}

High pressure (HP) hydraulic descaling operation is widely used to remove the scales formed on the surface of hot strip steels after preheating furnace and during hot rolling. These scales, so-called rolled-in defects, affect significantly the surface quality of the hot rolled products and reduce the life time of work rolls. Generally, the following types of scale formation are distinguished ${ }^{1)}$ :

- Primary scale, formed during reheating in the rolling mill furnace.

- Secondary scale, formed after descaling by the edging pass and during and after the roughing operation.

- Tertiary scale, formed during final rolling before and in between the stands of the finishing mill.

According to the detailed analysis by Blazevic, ${ }^{2)}$ rolledin scale on products of a hot strip mill can lead to approximately 30 related surface defects.

Different methods are usually used to control the rolledin scale formation, including low temperature of the strip at the entry, descaling, inter-sand cooling, skin cooling, roll cooling, and lubrication. Among them, the descaling operation is one the most frequent method to remove primary and secondary scales from strip steels. Traditionally, HP flat spray nozzles are used in this application in slab, billet or bloom operations. The force of the spray impinges the steel surface breaking up the scale and moving it away. Optimiz- ing header design can help improve product quality and reduce energy costs for the mill.

In order to improve productivity and quality, steel industries are adopting process modeling techniques to reduce defects, scrap, design lead time and cost. ${ }^{3)}$ Many process models have so far been presented for water spray cooling of hot-rolled steel bars. ${ }^{4,5)}$ Nevertheless, less systematic work has been published on modeling of HP hydraulic descaling using flat spray nozzles. Previous studies have been done to determine the mechanisms of scale removal. ${ }^{6-9)}$ An analytical model was proposed by Wada et al. correlating the impact pressure of the hydraulic descaling with the water consumption at a pressure $9.8 \mathrm{MPa}$, water pressure, rolling speed, and distance between the material and the nozzle based on the measurements using both a plasticine and pressure converter. ${ }^{10)}$ Recently, a computer model was introduced to study the stresses that develop within the oxide formed on the surface of reheated steel slabs. ${ }^{11)}$ A criterion based on the velocity and amount of water as well as the force of the impact was proposed to determine the feasibility for oxide removal using HP descaling nozzles. Some steel industries have also developed private simulation programs for their own spray nozzles. ${ }^{12,13)}$

Due to the complexity of the turbulent, two-phase spray formed during the operation, available numerical models can not be used to study the fluid mechanics of the system. The physical modeling of the process is not possible either, 
as the real system works out under very high spray pressure (e.g. 200-400 MPa). Artificial neural network (ANN) is a very powerful tool to model such complicated system. This approach is in fact a non-linear statistical analysis technique that is suitable for simulation of systems which are hard to be described by physical models.

A combined analytical-artificial neural network (AANN) model is recently developed for the first time by the present authors to improve the efficiency of a single HP flat spray nozzle based on achieving the maximum spray impact. ${ }^{14)}$ In the AANN model, the spray impact of each spray was estimated by neural network, whereas the spray force and depth were computed by analytical relationships. In the present work, the AANN model has been extended to design spray nozzle arrangements and to specify the conditions for a maximum spray impact and an optimum overlap for any given nozzle assembly. The process parameters considered include spray pressure, water flow rate, spray angle, inclination angle, offset angle, horizontal distance between nozzles and vertical spray height. The ability of the model to predict spray impact, force, width, depth and overlap are discussed and the main controlling parameters of the descaling operation are evaluated.

\section{Model Theory}

\subsection{Descaler Parameters}

Hydraulic descaling nozzles are normally flat (jet) spray nozzles. Figure 1 shows schematic of positioning of spray nozzles. ${ }^{15)}$ The exact definition of the spray characteristics such as spray angle, width, depth (thickness), and impact distribution, and the specification of the operation parameters such as spray pressure, flow rate, and vertical height are the first two steps to be taken when a spray nozzle is being designed.

Since the water droplets are immediately acted upon by external forces (e.g. gravity and moving gases), the spray angle is measured close to the nozzle orifice. This phenomenon is called spray 'convergence'. Four spray angles describing the width of the spray are very common: $22^{\circ}, 26^{\circ}$, $30^{\circ}$, and $40^{\circ}$ nozzle tips, each available at different flow sizes. In order to achieve design flexibility, the spray width is identical for all nozzle tip sizes at identical pressures and

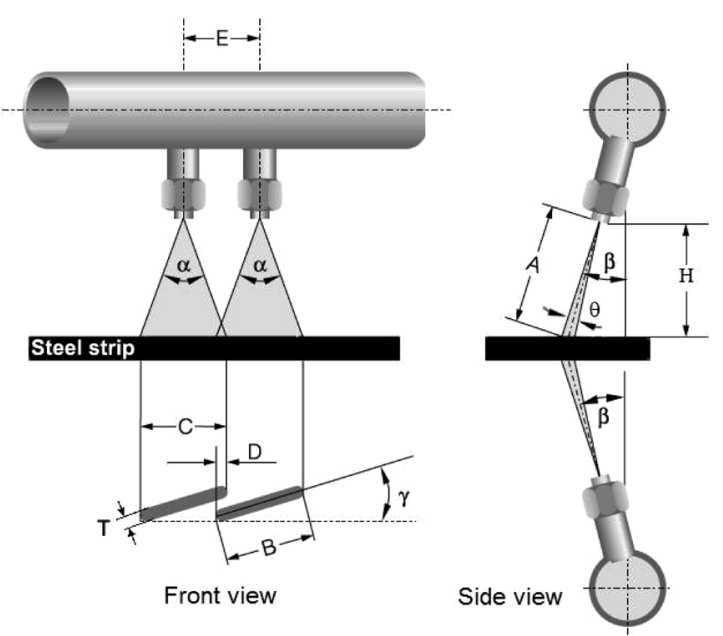

Fig. 1. Schematic of positioning of HP descaling spray nozzles. spray heights. $^{15)}$

Having selected a particular nozzle type (size and spray angle), the force depends only on the water pressure and the water flow. If the water pressure is fixed and limited as in many existing installations, the only variable to play with is the area of impact. Spray angle and spray thickness (depth) are the two nozzle design parameters affecting the area of impact. It is also fact that with an increasing inclination angle both the spray width and the spray thickness grow. Hence the area of impact increases, consequently lowering the impact.

The vertical spray height also plays an important role as it has a direct effect on the spray width, and hence on the area of impact. Significant improvements could be achieved in both product quality and cost savings in existing rolling mills by reducing the spray height.

In the following sections, the artificial neural network and analytical models developed to estimate the spray impact, width, depth, force and overlap will be presented.

\subsection{The Neural Network Model}

\subsubsection{Why Neural Network?}

The theoretical maximum impact is the theoretical force that the nozzle will produce along the centerline of the spray pattern provided there are no losses in the nozzle. A specific spray impact can be defined as impact per unit impingement area of the entire spray pattern:

$$
I_{\mathrm{m}}=\frac{F_{\mathrm{t}}}{B \cdot T}
$$

where $I_{\mathrm{m}}$ is the specific impact $\left[\mathrm{Nmm}^{-2}\right], B$ is the spray width [m] and $T$ is spray depth or thickness [m] (see Fig. 1). Spray angle and spray concentration are important variables in determining specific impact. Smaller spray angles will have a smaller impingement area with more drops per unit area. The smaller the impingement area of the spray, the higher the specific impact is of the spray pattern produced. Impingement area $\left(A_{\mathrm{I}}\right)$ can be calculated via the following equation:

$$
A_{\mathrm{I}}=2 \cdot H \cdot \tan \left(\frac{\alpha}{2}\right) \cdot 2 \cdot H \cdot \tan \left(\frac{\theta}{2}\right)
$$

where $H$ is the spray height (vertical distance from the nozzle tip to measuring area on the strip surface, see Fig. 1) [m], $\alpha$ is the spray angle and $\theta$ is the lateral spray angle. Trigonometry can estimate the impingement area but as the spray height increases, the error percentage of Eq. (2) increases. The lateral spray angle, $\theta$, and the (transverse) spray angle, $\alpha$, are only accurate close to the orifice.

The spray impact depends on the spray width and depth. ${ }^{16)}$ The impact increases when spray width or depth decrease. The impact also increases when pressure or flow rate increase. But the increasing pressure also influences the spray width and depth that influences the impact again. It can be seen that, the process parameters are highly dependent on each other. Another complication is the spray convergence. Depending on pressure and capacity, the spray tends to start to pull in as it leaves the orifice. Therefore, it is not possible to analytically compute the real impingement area. Therefore, individual functions have to be devel- 
oped for every nozzle type and process conditions.

Due to the complications described above, an artificial neural network (ANN) approach was used to estimate the spray impact and spray width under any given condition. ANN is a very powerful tool to model the relationship between the input and output parameters of complicated systems such as hydraulic descaling. This approach is a nonlinear statistical analysis technique, especially suitable for simulation of systems which are hard to be described by physical models. ${ }^{17)}$ It provides a way of linking input data to output data using a set of non-linear functions. The network architecture and the training procedure are discussed in the following sections.

\subsubsection{Network Architecture}

In this work, a standard feed-forward network with two hidden layers was designed by a trial and error procedure. The number of neurons in the input and output layers are determined by the number of input and output variables, respectively. In order to find an optimal architecture, different numbers of neuron in the hidden layer were considered and root-mean-square (RMS) error for each network was calculated. Figure 2 shows the schematic representation of the neural network architecture employed in this study. The input layer included five variables of spray pressure, water flow rate, spray angle, inclination angle and vertical spray height. The output variables of the model were spray impact, spray width and spray depth. As shown in Fig. 2, two hidden layers were used in the network; the first layer consists of ten neurons while the second layer has nine neurons. The spray impact and spray width were used to analytically compute spray force and overlap as explained in Sec. 2.3.

\subsubsection{Training Process}

ANN models are often trained by the 'backpropagation' method. ${ }^{18)}$ The term backpropagation refers to the manner in which the gradient is computed for non-linear multilayer networks. The early standard algorithm consisted of assigning a random initial set of weights to the neural network, then presenting the data inputs, one set at a time, and adjusting the weights with the aim of reducing the corresponding output error. This was repeated for each set of data and then the complete cycle was repeated until an acceptably low value of the sum of squares error was achieved. Such an algorithm is usually both inefficient and unreliable, requiring much iteration to converge if it converges at all. Therefore a number of variations of the standard algorithm (based on other optimization techniques) have been developed. One of the most useful and fastest algorithms is Levenberg-Marquardt. ${ }^{18)}$ A potential difficulty with the use of such algorithm is over fitting. In this situation, the network is said to be memorizing data patterns rather than predicting them. One way to reduce this problem is employing Bayesian regularization.

In this study, Bayesian regularization was used to improve the ability of the network for predicting more precise results from unseen input patterns. All available data from the hot strip mills of Mobarakeh Steel Complex (MSC) were divided into two parts: 37 sets for training procedure and 10 sets for test. ${ }^{19)}$ In order to improve the network per-

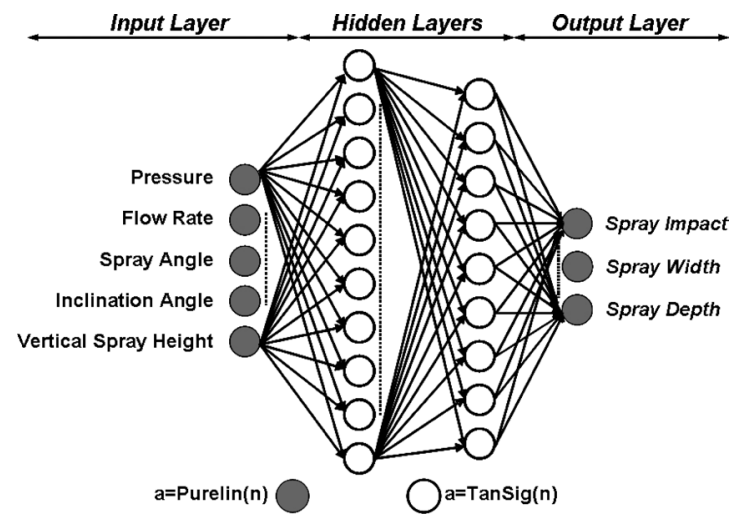

Fig. 2. Schematic of the neural network model (the connectors of all neurons are not shown for simplicity).

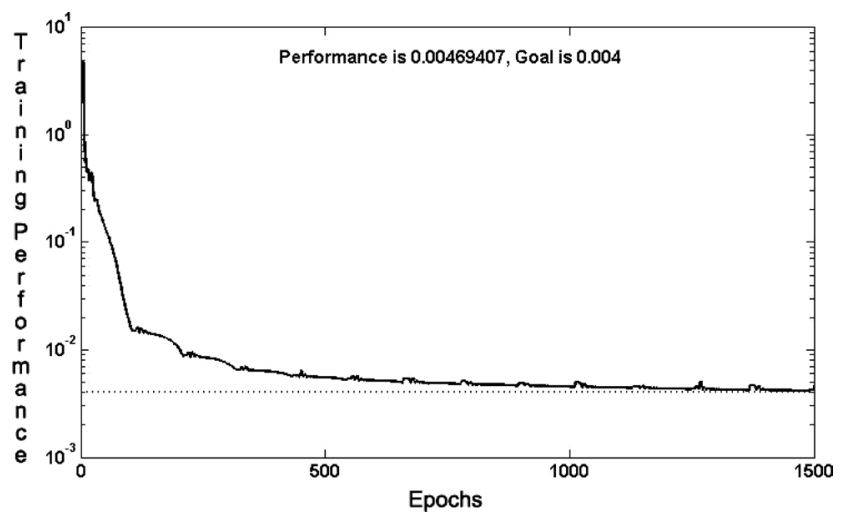

Fig. 3. Training curve of the neural network model.

formance, inputs and outputs were normalized in the range of -1 to 1 . Figure 3 shows the training curve of the ANN model. The training performance shown in Fig. 3 is in fact the mean square error (MSE) calculated via the following equation:

$$
\mathrm{MSE}=\left(\frac{1}{N} \sum_{1}^{N}\left|t_{i}-p_{i}\right|\right)^{2}
$$

where $N$ is the total number of comparison operations (that is equal to the number of input variables times number of datasets), $t_{i}$ is the target value and $p_{i}$ is the predicted value. It can be seen that the performance is about 0.0047 for the goal 0.004. Several intentional disturbances have been also applied after about 500 epochs, but the same performance was again achieved.

\subsection{The Analytical Model}

\subsubsection{Spray Force}

No nozzle can exceed the theoretical total force. This force is the same for all nozzles of the same flow rate and pressure:

$$
F_{\mathrm{t}}=\rho Q V
$$

where $F_{\mathrm{t}}$ is the total impact force [N], $\rho$ is density $\left[\mathrm{kg} \mathrm{m}^{-3}\right]$, $Q$ is flow rate $\left[\mathrm{m}^{3} \mathrm{~s}^{-1}\right]$, and $V$ is velocity $\left[\mathrm{m} \mathrm{s}^{-1}\right]$. All the above variables affect the flow rate and velocity of the spray, which in turn affects impact. The impact is the most important parameter of spray descaling. The spray impact is controlled by mass per unit time, spray angle, concentration 
of the spray, operating pressure, drop size and air friction. Mass per unit time is the product of the density and flow rate. Velocity is affected by drop size in that smaller drops lose velocity faster due to air friction. Larger drops will maintain velocity further from the orifice.

The final force equation for a water spray can be reduced to $^{20)}$ :

$$
F_{\mathrm{t}}=0.235 Q \sqrt{P}
$$

where $Q$ is the flow rate [ $\mathrm{L} \mathrm{min}^{-1}$ ] and $P$ is pressure [bar]. The theoretical total force that the nozzle can produce is a valuable number. Nevertheless, in order to compare this number to the actual measured values of the spray force, more mathematics needs to be applied.

\subsubsection{Spray Overlap}

For uniform descaling over the entire width of the rolled stock it is essential to also ensure a uniform impact of all jets spraying in one row. The nozzle spacing and the pitches between them are not only directly related to the spray height and spray angle, but also to the overlap of two adjacent spray jets (see $D$ in Fig. 1 as the spray overlap). Each descaling nozzle shows a certain unavoidable drop in impact at both edges of the spray jet. The width of the overlap of two adjacent spray jets must be equal to the width of the edge drop. ${ }^{16)}$ On the other hand, undescaled strips on the surface can be caused by excessive overlap. ${ }^{16)}$ In such a case, the spray jet of the nozzle sitting behind the adjacent one creates a water layer on the surface which drastically reduces the impact in the overlap area. Therefore, the value of spray overlap must be optimized for each nozzle configuration.

Knowing the values of spray width, offset angle and the horizontal distance of spray nozzles, the value of spray overlap $(D)$ can be computed by the following equation ${ }^{15)}$ :

$$
D=B \cos (\gamma)-E
$$

where $E[\mathrm{~m}]$ is the horizontal distance between nozzles. Inserting the value of spray width $(B)$ from the ANN model, the spray overlap can be estimated.

\subsection{The Descaling Modeling Strategy}

The complete structure of the modeling procedure for HP descaling operation using both ANN model along with the analytical relationships is shown in Fig. 4. The input parameters include spray pressure, water flow rate, spray angle, inclination angle, offset angle, vertical spray height and horizontal distance between the nozzles. The whole model is able to estimate value of spray impact, spray force, spray width, spray depth and spray overlap.

\section{Results and Discussion}

\subsection{The Importance of Spray Impact}

Figure 5 shows the pictures of an aluminum sheet surface operated under two different spray descaling conditions: (a) low spray impact (bad design) and (b) high spray impact (improved design). These results were achieved under the pressure 180 bar and the same spray height, but different nozzle designs. ${ }^{19)}$ Frankly, the higher and more concentrated the spray impact, the better descaling opera-

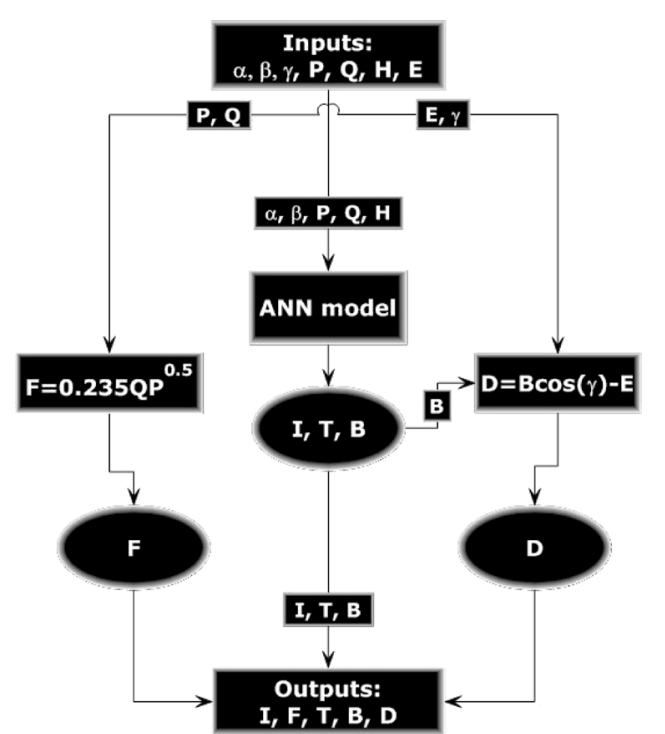

Fig. 4. The complete structure of the modeling procedure for HP descaling operation of hot strip steels.
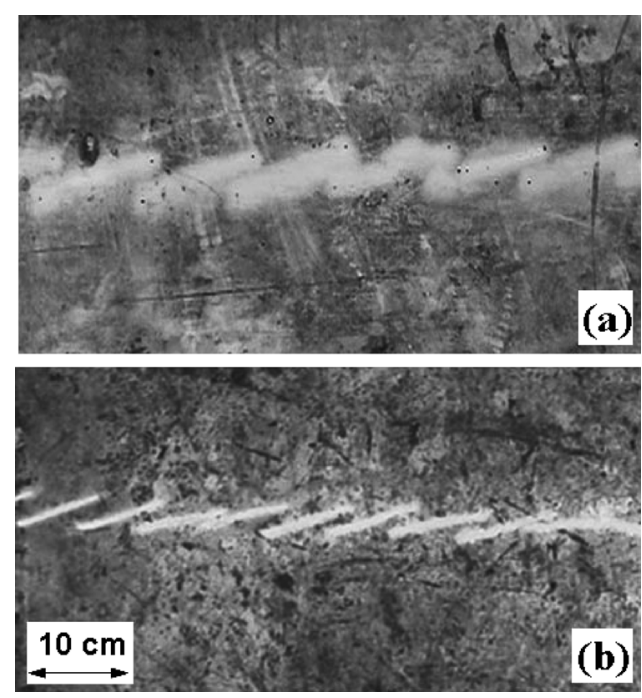

Fig. 5. Real pictures of an aluminum sheet surface operated under two different spray descaling conditions: (a) low spray impact and (b) high spray impact.

tion (Figs. 5(b) vs. 5(a)). The objective is then to specify the process conditions for achieving a maximum amount of spray impact for any given spray configuration. In this regard, the relationship between different parameters should be taken into account.

\subsection{Model Validation}

The performance of the ANN model was evaluated against 10 unseen (test) industrial dataset (out of 47 total datasets; that is $\sim 21 \%$ ) under different nozzle configurations and process conditions. Figure 6 compares the predicted spray impact by the present ANN model with the industrial one for all unseen datasets. As an example, the last point in Figure 6 corresponds to the following conditions: $\alpha=26^{\circ}, P=150$ bar, $Q=109 \mathrm{~L} \mathrm{~min}^{-1}, \beta=10^{\circ}, \gamma=15^{\circ}, H=$ $100 \mathrm{~mm}$, and $E=98 \mathrm{~mm}$. For such conditions, the predicted spray impact by the ANN model is about $1.38 \mathrm{~N} \mathrm{~mm}^{-2}$ that is close to the industrial value of $1.32 \mathrm{~N} \mathrm{~mm}^{-2}$. Although the use of Bayesian regularization may result in a higher 


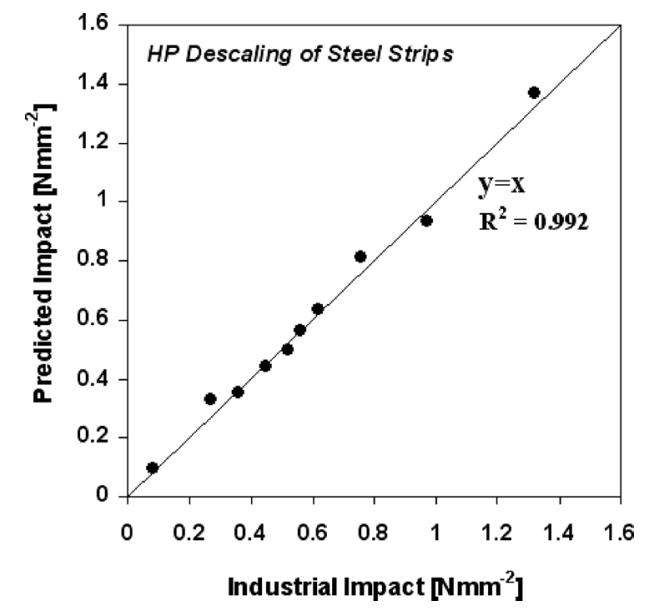

Fig. 6. Comparison between the predicted and industrial values of the spray impact for the unseen (test) datasets.

Table 1. Nominal range of different input parameters of the ANN model.

\begin{tabular}{|lccc|}
\hline \multicolumn{1}{|c}{ Parameter } & \multicolumn{2}{c}{ Value } & Unit \\
\cline { 2 - 3 } & Min & Max & \\
\hline Spray angle & 22 & 40 & $\operatorname{deg}$ \\
\hline Inclination angle & 5 & 15 & $\operatorname{deg}$ \\
\hline Spray pressure & 140 & 300 & bar \\
\hline Water flow rate & 18 & 214 & $1 \min ^{-1}$ \\
\hline Vertical spray height & 50 & 470 & $\mathrm{~mm}$ \\
\hline
\end{tabular}

performance error for the training datasets, the error for the test datasets are reduced which is an indication of higher ability of the network to predict more precise results from unseen patterns. A good agreement can be seen in Fig. 6 with the correlation coefficient (R-squared) of about 0.992, showing the ability of the ANN model to predict the accurate results.

\subsection{Parameter Sensitivity}

The validated ANN model was used to study the contributions of different parameters on the spray impact and overlap and hence, the efficiency of the descaling operation. To perform such sensitivity analysis, the nominal working range for the considered input parameters were specified as shown in Table 1. Each individual input parameter was changed with the increment 0.1 at the mean values of all other parameters. The spray impact and spray overlap versus each individual parameter were then evaluated.

Figure 7(a) shows the effect of spray angle on the spray impact and spray overlap in the entire range of $22^{\circ}$ to $40^{\circ}$. It can be seen that increasing the spray angle decreases the spray impact but increases the spray overlap. The slope of this curve at each value, or the local first derivative, is an indication of the impact and overlap sensitivities to the spray angle. The variation data were calculated by the SigmaPlot software. These data show the variation rate of spray impact and spray overlap with respect to each process parameter. Figure 7(b) shows the variation of spray impact and spray overlap for different spray angles. It is shown that
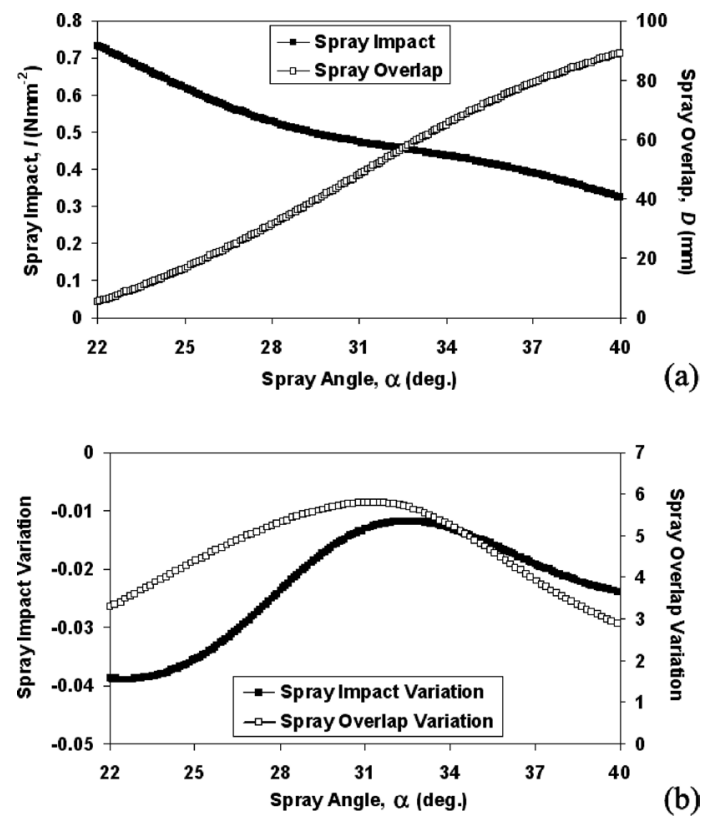

Fig. 7. Effect of spray angle on (a) the spray impact and spray overlap and (b) their variations.
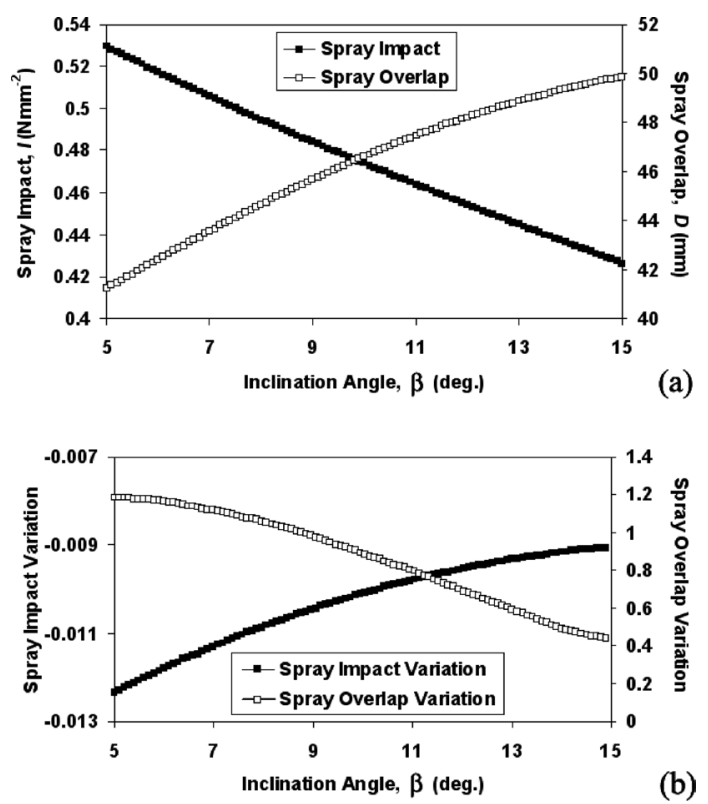

Fig. 8. Effect of inclination angle on (a) the spray impact and spray overlap and (b) their variations.

the effect of spray angle on the impact is higher for the lower and upper limits than the median values. The same trend can be seen for the spray overlap.

Figure 8(a) shows the effect of inclination angle on the spray impact and spray overlap in the entire range of $5^{\circ}$ to $15^{\circ}$. It can be seen that increasing the inclination angle decreases the spray impact but increases the spray overlap. Figure 8(b) shows that the effect of inclination angle on the impact is higher for the lower limit, but this effect on the overlap is higher for the upper values.

Figure 9(a) shows the effect of vertical spray height on the spray impact and spray overlap in the entire range of 50 to $470 \mathrm{~mm}$. It is shown that increasing the vertical spray height rapidly decreases the spray impact and increases the spray overlap. Figure 9(b) shows that the maximum varia- 

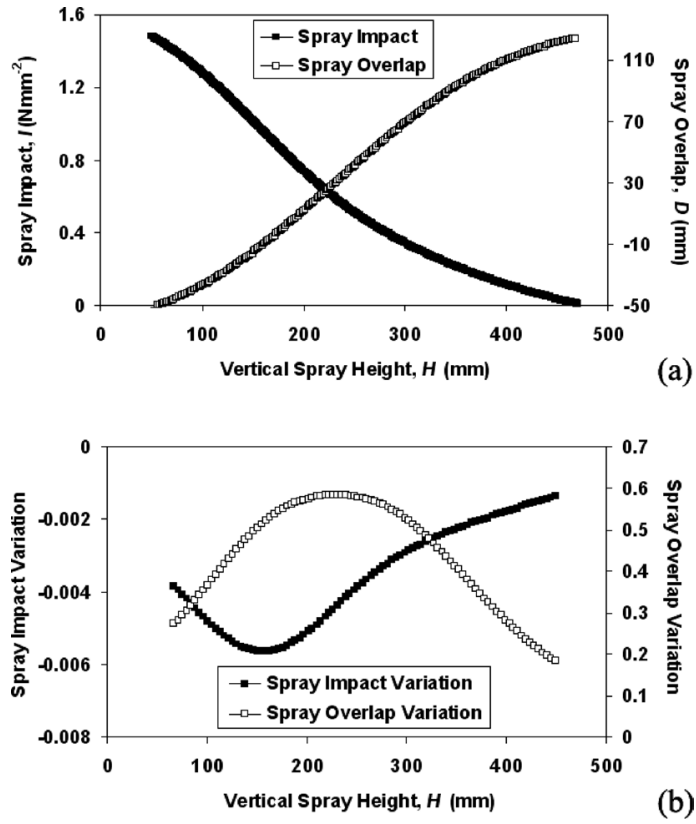

Fig. 9. Effect of vertical spray height on (a) the spray impact and spray overlap and (b) their variations.

tion of impact is occurred at about $150 \mathrm{~mm}$ of the spray height, but the maximum variation of the spray overlap is achieved in the lower and upper limits of the spray height.

Figure 10(a) shows the effect of spray pressure on the spray impact and spray overlap in the entire range of 140 to 300 bar. It can be seen that increasing the spray pressure has a direct influence on the spray overlap but represents a peak for the spray impact. Figure 10(b) shows the same trend for the variation of both spray impact and overlap with the highest variations for the lower and upper limits. The reason for decreasing spray impact with increasing spray pressure is due to the practical method for increasing the pressure. In practice, using a given nozzle geometry, the only way to increase the pressure is by the water flow rate. As the variation of spray pressure in Fig. 10(a) is considered under the average value of the flow rate, it would be logic to achieve a lower spray impact for the higher pressure. When the value of spray pressure is considered to be increased as a function of water flow rate, the practical trend of the pressure will be achieved as shown in Fig. 10(c). As it was described before, the pressure increasing also influences the spray width and depth that influences the impact again. This clearly shows that the process parameters are highly dependent on each other.

Figure 11(a) shows the effect of water flow rate on the spray impact and spray overlap in the entire range 18 to $214 \mathrm{~L} \mathrm{~min}^{-1}$. It is shown that increasing the water flow rate has a direct influence on the spray impact, but represents a maximum for the spray overlap. Their variations shown in Fig. 11(b) indicate that the higher impact variation is occurred in the lower and upper limits, while the higher overlap variation is applied in the upper limit.

The contributions of different input parameters on the spray impact and spray overlap are compared in Figs. 12(a) and 12(b), respectively, using the normalized values of all parameters in their entire nominal range. Interestingly, it can be seen that the influence of these parameters on both spray impact and spray overlap decreases in the following
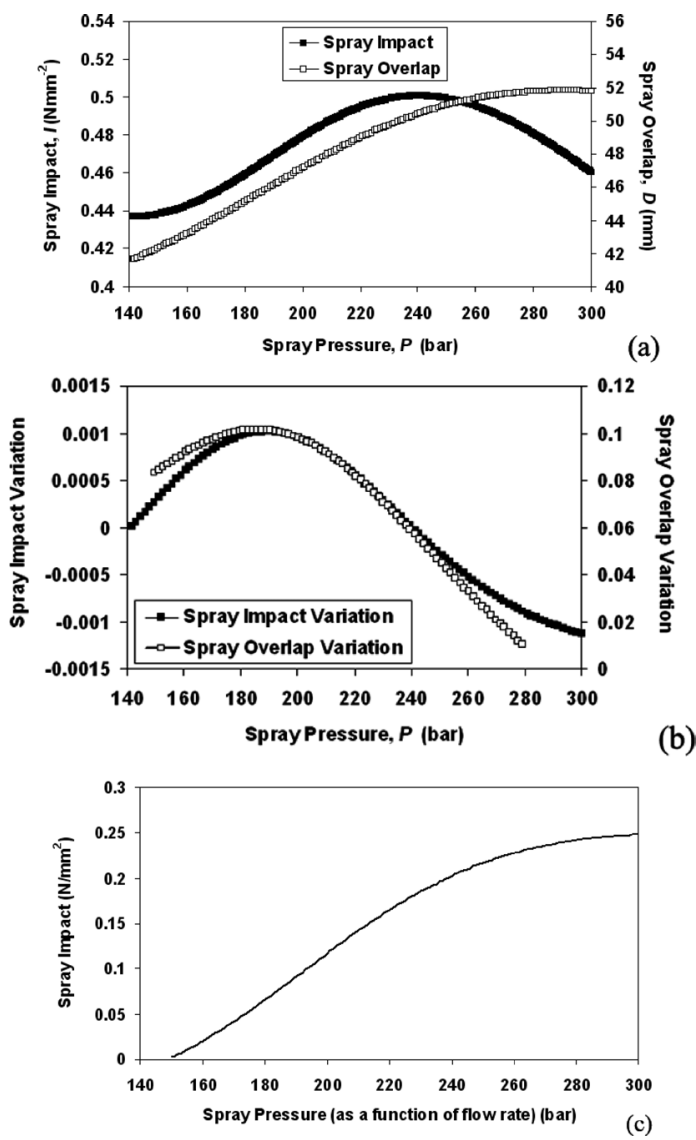

Fig. 10. Effect of spray pressure on (a) the spray impact and spray overlap, (b) their variations and (c) the spray impact considering the interrelationship between the spray pressure and water flow rate.
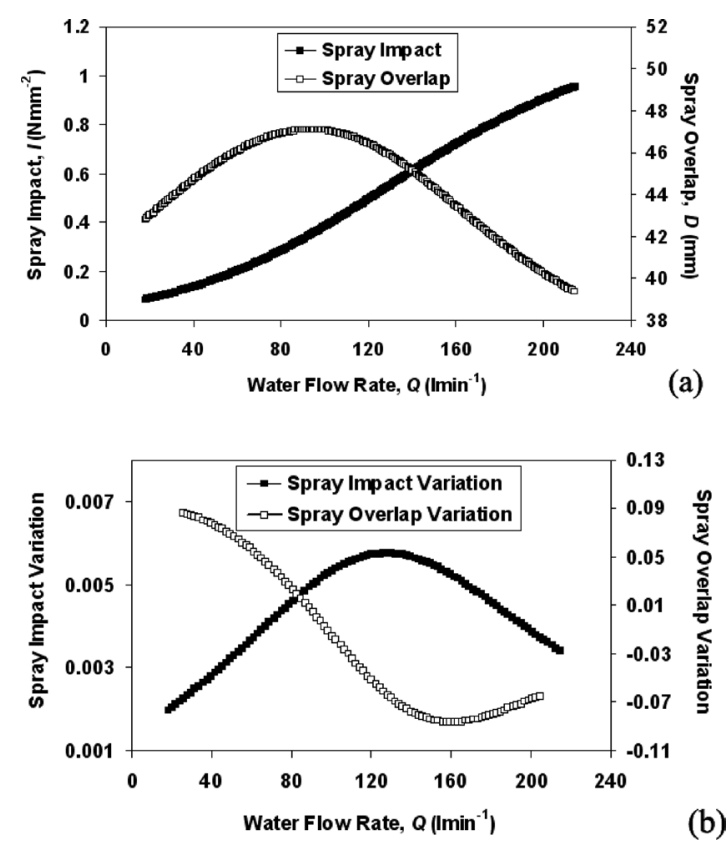

Fig. 11. Effect of water flow rate on (a) the spray impact and spray overlap and (b) their variations.

order: spray angle, inclination angle, vertical spray height, water flow rate, and spray pressure. Therefore, one can conclude that the descaling nozzle configuration with lower spray and inclination angles positioned in a low vertical spray height would increase the spray impact, consequently 

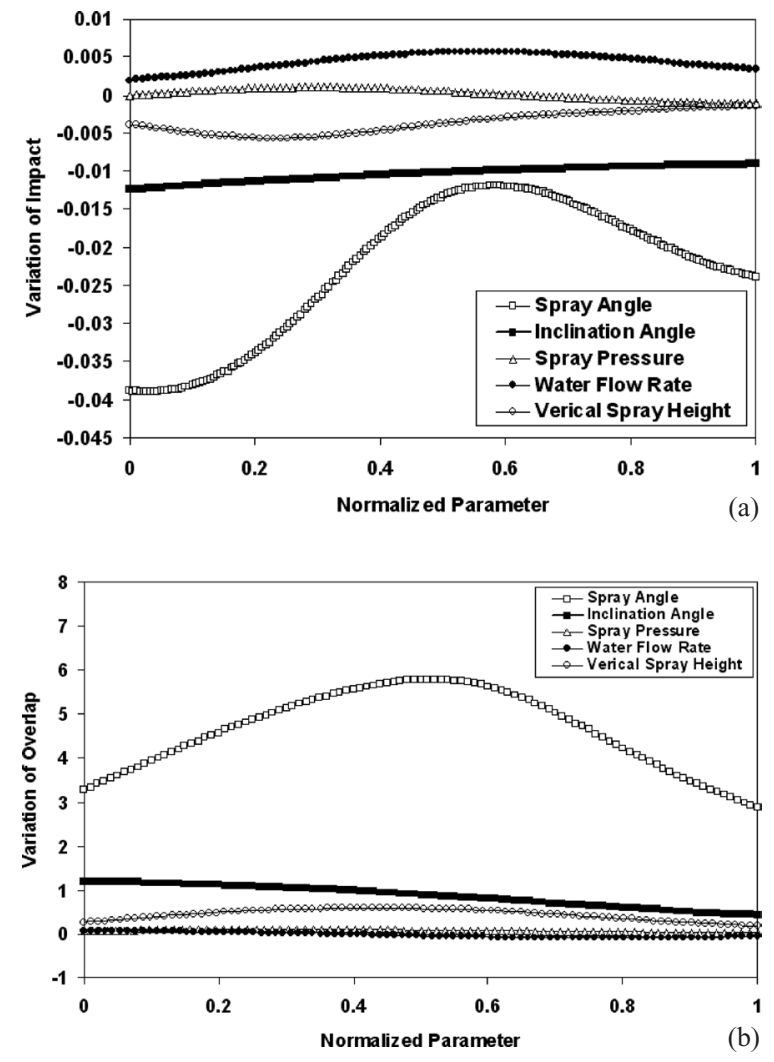

Fig. 12. Comparison of the contributions of the input parameters on the variation of (a) spray impact and (b) spray overlap under normalized condition.

the efficiency of the descaling operation.

According to the above discussion, the spray angle, inclination angle and vertical spray height are the main process parameters for the HP descaling operation. In practice, the inclination angle is usually selected in the median value $10^{\circ}$. It would be useful to consider the simultaneous influences of both spray angle and vertical spray height on the spray impact and spray overlap. These effects are shown in Figs. 13(a) and 13(b), respectively. It is seen that the maximum impact is achieved for both lower spray angle and lower vertical spray height. The effect of spray angle on spray impact is more for the lower values of vertical spray height. The maximum spray overlap is achieved for both higher spray angle and higher vertical spray height. The negative values of spray overlap achieved for low values of both spray angle and vertical spray height means no overlap. Under these conditions, undescaled stripes will be remained on the surface of the steel strip. Undescaled stripes on the strip surface can also be caused by excessive overlap. Therefore, the optimum value for the spray overlap must be specified for each nozzle design. The width of the overlap of two adjacent spray jets must be specified based on the width of the edge drop. Nozzles from different manufacturers show different (sharper or softer) edge drop. Consequently, it is important to define the edge drop for each nozzle family. Some manufacturers use about $30 \%$ of the spray width as the optimal spray nozzle overlap. ${ }^{21)}$ It is claimed that since the edges of the spray flow less than the center portion, the overlapping of the spray patterns to about $30 \%$ of the spray width help equalize the flow distribution across the target. However, in some application $100 \%$ or more
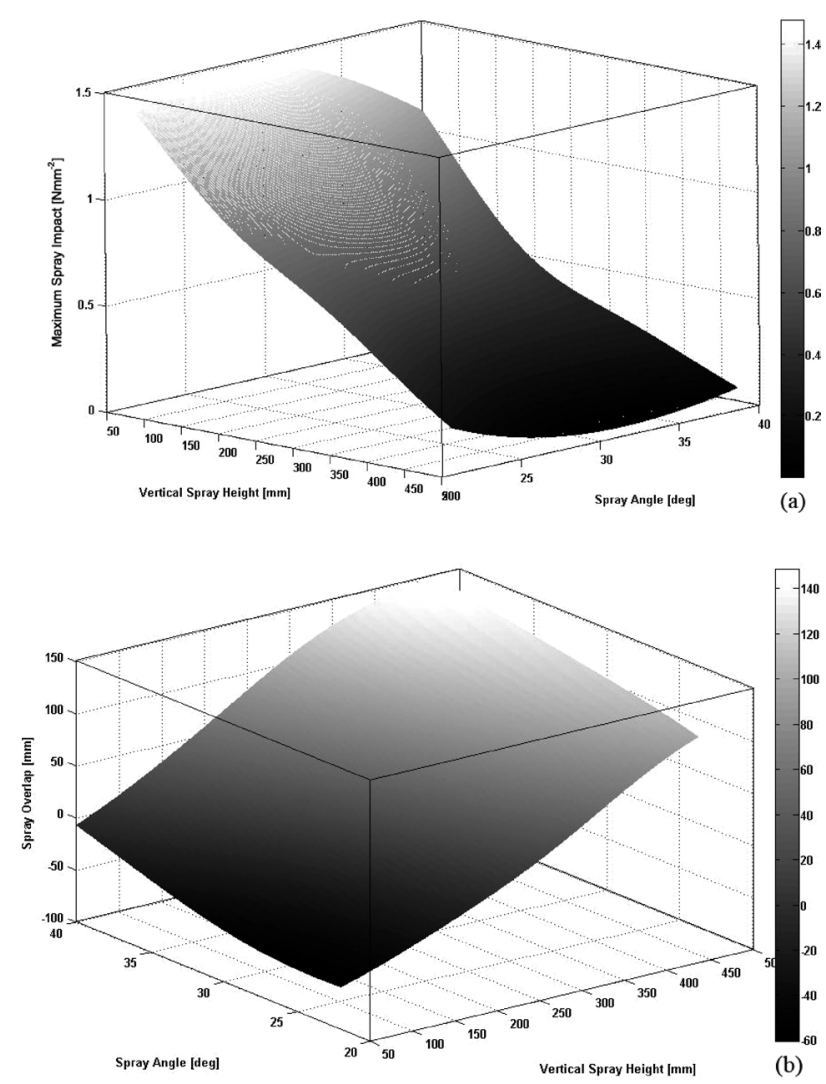

Fig. 13. Simultaneous influences of the spray angle and vertical spray height on the (a) spray impact and (b) spray overlap.

overlap is required if there is a potential for nozzle pluggage problems. ${ }^{21)}$

\section{Conclusions}

A combined analytical-artificial neural network modeling strategy was presented to evaluate the efficiency of the high pressure hydraulic descaling operation of hot strip steel rolling. The efficiency improvement was based on achieving a maximum amount of spray impact and an optimum amount of spray overlap. An artificial neural network model within a Bayesian framework was used to predict the spray impact, spray width and spray depth, whilst the spray force and spray overlap were predicted analytically in the model. The model was validated against several experimental data from an industrial hot strip mill. It was found that among all the process parameters of spray angle, inclination angle, vertical spray height, spray pressure and water flow rate, the most important one is the spray angle; its lower value results in a higher impact and lower overlap. The inclination angle is also an important parameter affecting the impact and overlap. The presented model is able to design any high pressure spray nozzle configuration and to evaluate the spray impact and overlap for any given process parameters.

\section{Acknowledgements}

The authors would like to acknowledge the financial support of Mobarakeh Steel Complex of Iran according to the contract no. 48114345-166. They also appreciate the assistance of Dr. M.R. Toroghinejad and Mr. Sh. Abbasi for 
their comments.

\section{REFERENCES}

1) M. W. Wolf: Iron Steelmaker, 63 (2000), July, 21.

2) D. B. Blazevic: Proc. of the 2 nd Int. Conf. on 'Hydraulic Descaling in Rolling Mills,' IoM, London, UK, (1997).

3) B. A. Mueller and Ph. Monaghan: J. Met., 46 (1994), 17.

4) P. C. Campbell, E. B. Hawbolt and J. K. Brimacombe: Metall. Mater. Trans. A, 22A (1991), 2769.

5) R. Thomas, M. Ganesa-Pillai, P. B. Aswath, K. L. Lawrence and A. Haji-Sheikh: Metall. Mater. Trans. A, 29A (1998), 1485.

6) G. A. Brown and K.-Ch. Chiang: Proc. of the $34^{\text {th }}$ Mechanical Working and Steel Processing Conf., Iron and Steel Society, Warrendale, PA, (1992), 439.

7) K. M. Browne, J. Dryden and M. Assefpour: Proc. of the 1995 ASME Int. Mechanical Engineering Cong. and Exposition, ASME, (1995), 187.

8) D. T. Blazevic: Proc. of the 2nd European Rolling Conf., Vasteras, Sweden, (2000), 1 .

9) N. J. Silk: Steel Times Int., 25 (2001), 38.

10) T. Wada, M. Ueda and M. Oshimi: Tetsu-to-Hagané, 77 (1991),
1450.

11) J. Ramirez-Cuellar, M. P. Guerrero-Mata, L. A. Leduc and R. Colas: Proc. of the 2nd Int. Conf. on Thermal Process Modelling and Computer Simulation, EDP Sciences, France, (2000), 209.

12) S. Schurmann: Proc. of Hydraulic Descaling Conf., Verlag Stahlisen GmbH, Düsseldorf, (2000), 1.

13) A. Kermanpur, A. Ebnonnasir, M. Hedayati, M. R. Toroghinejad and A. R. Keyyeganeh: Proc. of Steel Symp. 85, AmirKabir University of Technology, Tehran, Iran, (2007), 251.

14) A. Kermanpur, A. Ebnonnasir and M. Hedayati: MST, 23 (2007), 951.

15) Scalemaster HP (High Performance), Industrial Catalogue, Lechler $\mathrm{GmbH},(2001)$

16) J. W. Frick: MPT Int., 27 (2004), 90.

17) H. K. D. Bhadeshia: ISIJ Int., 39 (1999), 966.

18) Z. Guo and W. Sha: Comput. Mater. Sci., 29 (2004), 12.

19) Technical Report, Mobarakeh Steel Complex, (2006).

20) L. Robb: Technical Report, Spraying Systems Co., Wheaton, USA, (2002).

21) Flat Spray Nozzles for Washing and Cleaning Applications, Industrial Catalogue, Technical Products and Services, Inc., Columbia, USA, (2006), 1. 